\title{
GLOVES PUNCTURE IN GENERAL DENTISTRY.
}

1. BDS, MSc Trainee

Department of Community Dentistry

Faculty of Dentistry LUMHS,

Jamshoro.

2. BDS, MSc

Associate Professor

Department of Oral Biology

Faculty of Dentistry LUMHS,

Jamshoro.

3. BDS, FCPS

Associate Professor

Department of Oral \& Maxillofacial Surgery

Faculty of Dentistry LUMHS,

Jamshoro.

4. BDS, MSc

Assistant Professor \& Incharge Community Dentistry Department

Faculty of Dentistry, LUMHS,

Jamshoro.

Correspondence Address:

Dr. Suneel Kumar Punjabi

Flat No: $3073^{\text {rd }}$ Floor Citizen Plaza

Opp Aga Khan Hospital.

Main Jamshoro Road, Qasimabad,

Hyderabad.

drsunilpanjabi@yahoo.com

Article received on:

19/06/2018

Accepted for publication:

28/03/2019

Received after proof reading:

$30 / 09 / 2019$
Priya1 $^{1}$, Munir Ahmed Banglani ${ }^{2}$, Suneel Kumar Punjabi ${ }^{3}$, Shazia Parveen ${ }^{4}$

ABSTRACT... Objectives: The purpose of current study was to identify particular procedures which are associated with a high risk of glove puncture and thereby assist in limiting the risk of infection, especially those in high risk group. Study Design: Observational study. Setting: Outpatient department of dentistry at Liaquat University hospital, Hyderabad. Period: August 2017 to January 2018. Materials and Methods: In present study gloves perforation were assessed after performing various dental treatments by using Latex Biogel gloves. Total 400 gloves were collected from department of oral and maxillofacial surgery, orthodontics, operative dentistry and prosthodontics, 100 from each department. Simple Water Inflation technique was used to test punctures in gloves to determine the number and position of punctures in used gloves. Data collection was done using SPSS version 22.0. Descriptive statistics were computed and differences between groups were assessed through $\mathrm{T}$ - test. P-value $\leq 0.05$ was taken as statistically significant. Results: Total 400 gloves were examined 100 from each department. Out of 100, 94 (94\%) were found perforated from oral \& maxillofacial surgery, 90 (90\%) from orthodontics, $73(73 \%)$ from prosthodontics \& 80 (80\%) from operative dentistry. Gloves puncture of left hand were more 292 (73\%) than that of right hand $108(27 \%)$ out of 400 gloves. Conclusion: Perforation of Gloves while several dental procedures have been evaluated and resulted that gloves on left hand were at greater risk unambiguously in the procedures in which wires were used, additional precautions like wearing double gloves during these procedures may therefore be indicated.

Key words: $\quad$ Gloves, Perforation, Surgical Procedures, Water Inflation.

Article Citation: Priya, Banglani MA, Punjabi SK, Parveen S. Gloves puncture in general dentistry. Professional Med J 2019; 26(10):1760-1764.

DOI: 10.29309/TPMJ/2019.26.10.4137

\section{INTRODUCTION}

Surgical procedures are aggressive in nature due to exposure of blood linked to high risk of transfer of pathogens. Contact between surgical team \& patients create an environment for transmission of microorganisms, ensuing post-surgical or blood borne infections in patients in the surgical team. Protection from infections is crucial for both patients and the surgical team. ${ }^{1}$

Dentists are at greater risk of having variety of infections due to exposure of microbes in their dental setup. Mucosa, respiratory tract, eyes and skin for most anchorage access for microbes ${ }^{2}$, treating all patients as they are infected is a significant preemptive protocol. ${ }^{2}$ using gloves to circumvent communicable infections through skin i.e. viral hepatitis \& HIV infection. ${ }^{3}$
In 1896 William Stewart Halsted introduce the gloves in medical sciences for the first time. ${ }^{4}$ Gloves must remain intact throughout procedure to be effective in avoiding contaminations. ${ }^{5}$

Though, gloves can become punctured \& their shielding function is then compromised. The occurrence of puncture is variable with diverse among gloves \& workers. ${ }^{5}$ The risk of puncture has been shown to increase significantly when gloves are worn for dental procedures lasting longer than 2 hours. ${ }^{6}$

Perforation usually occurs as a result of injuries from sharps, such as wires, sutures, instruments, bone fragments, doctors wearing jewelry and also through natural wear and tear. ${ }^{1}$ 
It may be considered that some dental procedures carry greater risk of glove puncture than others.

The purpose of current study was to identify particular procedures which are associated with a high risk of glove puncture and thereby assist in limiting the risk of infection, especially those in high risk group.

\section{METHODOLOGY}

An observational study was conducted in Outpatient Department of Dentistry at Liaquat University Hospital Hyderabad from August 2017 to January 2018.

In this study gloves perforation were assessed after performing various dental treatments by using Latex Biogel gloves (Made in Malaysia). Total 400 gloves were collected from department of oral \& maxillofacial surgery, orthodontics, operative dentistry and prosthodontics, 100 from each department. The following procedures were included in the study

- Fractures of facial bones

- Osteotomy

- Extractions

- Surgical removal of wisdom teeth

- Biopsy and removal of soft tissue lesions

- Incision and drainage of abscess

- Using orthodontics wires on patients

- Root canal treatment

- fillings

- Crown preparation, Partial denture insertion, periphery taking

Water Inflation technique was used to test the number and site of punctures on gloves, filling gloves with $0.5 \mathrm{~L}$ of water, applying gentle pressure and observing for punctures for 20 seconds. ${ }^{5,7}$ The numbers of punctures were noted with their location being patent on a chart. By this method it was possible to determine the number and position of punctures in used gloves. As a control, 50 unused gloves were also inflated as above and tested for defects/ punctures. The analysis of the results was done with SPSS version 22.0. Descriptive statistics were computed \& frequencies among groups were evaluated through T- test. P-value $\leq 0.05$ was taken as statistically significant. Results presented in tables and charts.

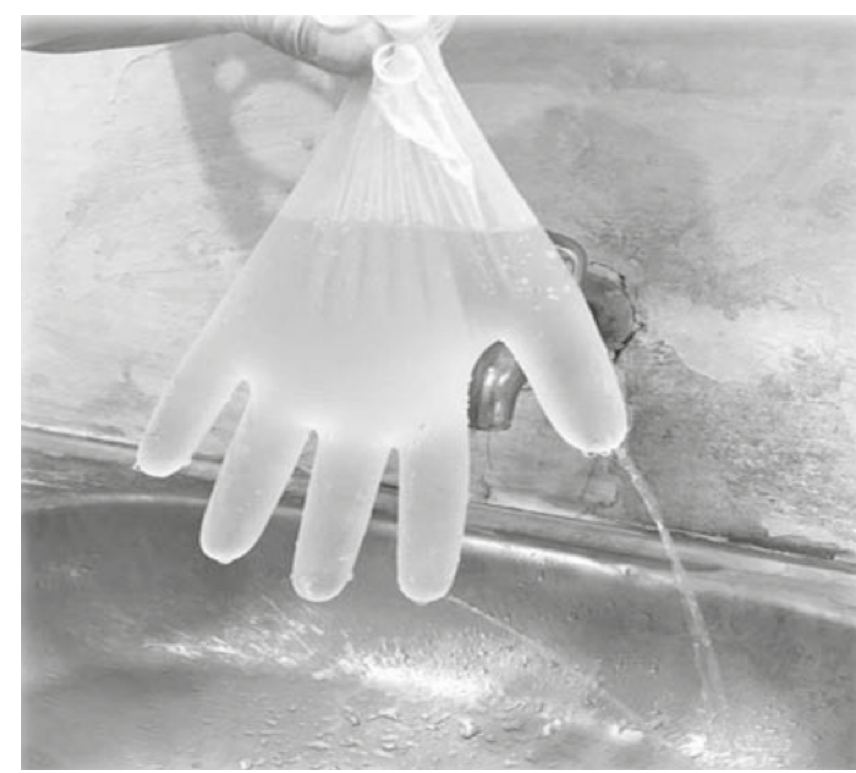

\section{RESULTS}

Total 400 gloves were examined 100 from each department. Out of 100, 94(94\%) were found perforated from oral \& maxillofacial surgery, $90(90 \%)$ from orthodontics, $73(73 \%)$ from prosthodontics \& $80(80 \%)$ from operative dentistry (Figure-1). Gloves puncture during different dental procedures from all 4 departments are shown in Table-I.

Gloves puncture of left hand were more 292 $(73 \%)$ than that of right hand $108(27 \%)$ out of 400 gloves. Common sites of gloves puncture is shown in Table-II

Control group had no punctures.

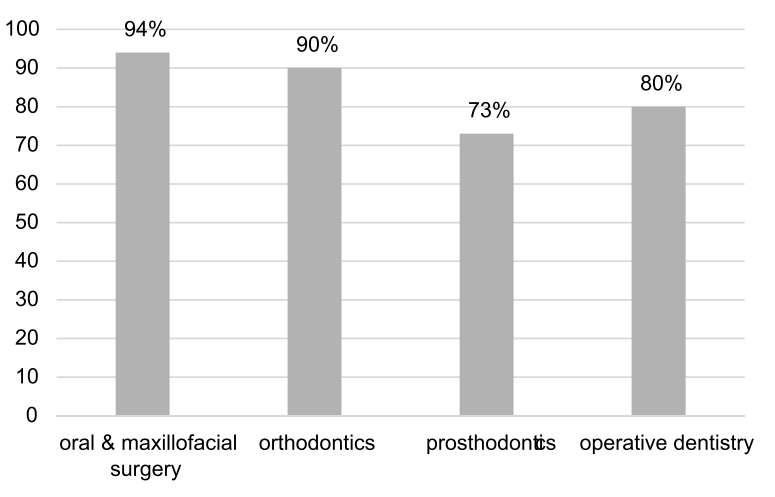

Figure-1. Distrubution of departments with gloves puncture 


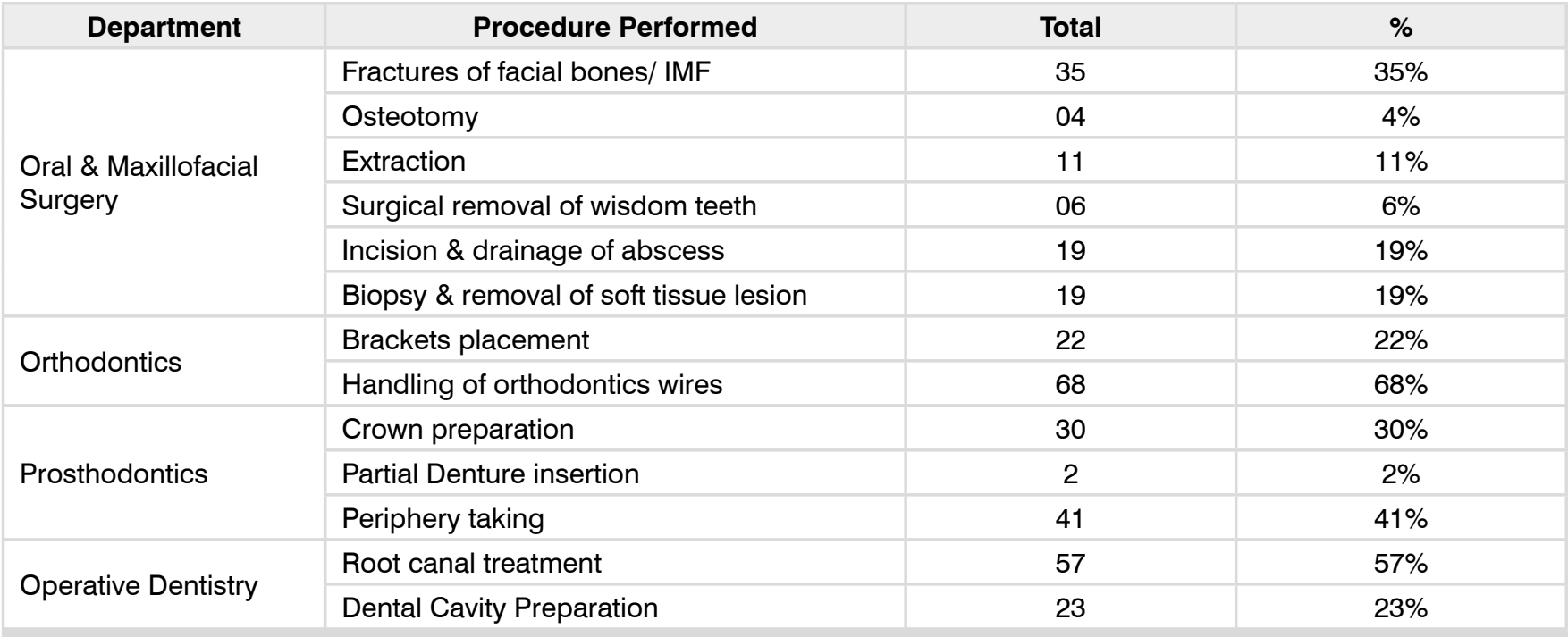

Table-I. Details of procedure by departments

\begin{tabular}{|l|c|c|c|c|}
\hline \multicolumn{1}{|c|}{ Site } & Right Hand & Left Hand & Total & \multicolumn{1}{|c|}{. } \\
\hline Index finger & 18 & 54 & 42 & 11.75 \\
\hline Middle finger & 11 & 36 & 43 & 10.75 \\
\hline Ring finger & 08 & 35 & 16 & 04 \\
\hline Little finger & 02 & 14 & 80 & 20 \\
\hline Thumb & 24 & 56 & 77 & 19.25 \\
\hline Palm & 29 & 48 & 65 & 16.25 \\
\hline Dorsum & 16 & 49 & & \\
\hline
\end{tabular}

Table-II. Description of gloves puncture according to site involvement

\section{DISCUSSION}

The outcomes of the contemporary study specify that sharp objects used in surgeries and other dental treatment punctures the gloves of doctor \& his assistant, with the highest risk for nonworking hand. According to previous studies index finger, particularly for left hand was predominantly susceptible for right handed doctors. ${ }^{8,9}$ overall gloves on the left hand (non-dominant) were puncture more frequently than right hand. The order for Glove perforations were thumb\& index finger of the left hand, dorsum, palm, middle finger, ring finger \& little fingers. These perforation spots are not unforeseen, as the left hand is frequently used to hold tissues being cut or sutured reposition or reach for needles / wires, or used as a retractor to defend adjacent tissue while cutting or suturing.

This study also shows that the oral \& maxillofacial surgery, orthodontic, prosthodontics \& endodontics perforations rate was 94\%, 90\%, $73 \%, 80 \%$ respectively, which is higher than the previous study in which perforation during these treatments were of $50 \%, 58 \%, 65 \%$ with over $90 \% .{ }^{10}$

This may be of precise significance through management of patients which are at greater risk of blood borne infection. The outcomes of contemporary study suggest that the doctor might be sensible to consider usage of double gloves in procedures in which wires are used. Wearing of Double gloves revealed improved fortification against infection transmission to the doctors from contaminated tissue and fluids of patients. ${ }^{11}$ Nevertheless, stabilization manual dexterity of doctor is crucial of this supplementary shielding. Numerous studies have exposed that perforation of inner gloves is being reduced/ prevented by using double gloves during various dental procedures e.g. oral surgery, endodontic 
treatment, prosthodontics treatment, periodontics treatment \& orthodontic treatment. ${ }^{12-14}$

A system for identifying intra-operative glove perforations tracking procedure is beneficial. ${ }^{15}$ A research had been done to investigate glove perforation indication system \& the results with double gloving in surgery of maxillofacial trauma, which concluded reduced rate of inner gloves as compare to outer gloves. Even though wearing two fold gloves might not prevent pungent injuries, it does intensify the force required for penetration, ${ }^{16,17}$ and could converse further protection due to "wipe off "result of dual glove layers. ${ }^{18}$

The outcome of extant study specifies the risk of glove perforation in maxillofacial surgical procedures is considerable. The results of previous studies show that perforation rate throughout a diversity of minor dental \& oral surgical procedures has vacillated from $4.1 \%$ to $16 \%{ }^{19-20}$

\section{CONCLUSION}

Perforation of Gloves while several dental procedures have been evaluated and resulted that gloves on left hand were at greater risk unambiguously in the procedures in which wires were used, additional precautions like wearing double gloves during these procedures may therefore be indicated.

Copyright@ 28 March, 2019.

\section{REFERENCES}

1. Khan M, Bagg PR. Glove perforation during oral \& maxillofacial surgical procedures. Pak Dent Oral J. 2016; 36-184-187.

2. Al-Dwairi ZN. Infection control procedures in commercial dental laboratories in Jordan. $J$ Dent Educ. 2007; 71:1223-227.

3. Public Health Service. Update U.S. Public health service guidelines for the management of occupational exposure to HBV, HCV and HIV and recommendations for postexposure prophylaxis. MMWR Recomm Rep. 2001; 50:1-52.

4. Sara Gaines, James N. Luo, Jack Gilbert, Olga Zaborina, et al. optimum operating room environment for the prevention of surgical site infections. Surg Infect. 2017; 18(4): 503-507. doi: 10.1089/sur.2017.020
5. Korniewicz DM, Rabuussay D. Surgical glove failures in clinical practice settings. AORN J. 1997; 66:660673.

6. Murray C A, Burke F, Mchugh S. An assessment of the incidence of punctures in latex and non-latex dental examination gloves in routine clinical practice. British Dental J. 2001; 190: 377 - 380 doi:10.1038/ sj.bdj.4800978.

7. Kritsaneephaiboon A, Mahaisavariya B. Glove perforation in orthopaedic trauma surgery. Thai $\mathrm{J}$ Orthopaedic Surg. 2006; 31:15-20.

8. Hussain SA, Latif ABA, Chaudhary AAAA. Risk to surgeons: $A$ survey associated injuries during operations. Br J Surg 1998: 75: 314-16.

9. Oliveira D, A.C., Gama, C.S. Evaluation of surgical glove integrity during surgery in a Brazilian teaching hospital. Am J Infect Control. 2014; 42:1093-1096.

10. Padhye MN, Girotra C, Khosla AR, Gupta KV. Efficacy of double gloving technique in major and minor oral surgical procedures: A prospective study. Ann Maxillofac Surg. 2011; 1(2): 112-119. doi: 10.4103/22310746.92771

11. Tlili MA, Belgacam A, Sridi $H$, Akouri M, et al. Evaluation of surgical glove integrity and factors associated with glove defect. Am J Infect Control. 2017: 29; 42: 176-182

12. Solda SC, Assef JC, ParreiraJG, Arantes GJ, et al. Undetected perforations of surgical gloves during emergency procedures, Rev. Assoc. Med. 2009: 55 (5) http://dx.doi.org/10.1590/S0104-42302009000500026.

13. Goldman AH, Haug E, Owen JR, Wayne JS, Golladay GJ. High risk of surgical glove perforation from surgical rotatory instruments. Clin Orthop Relat Res. 2016; 474:2513-17.

14. Martinez A, Han Y, Sardar ZM, Beckman L, et al. Risk of glove perforation with arthroscopic knot tying using different surgical gloves and high-tensile strength sutures. J Arthrosc Relat Surg. 2013; 29:1552-58.

15. Guo YP, Wong PM, Li Y. Is double-gloving really protective? A comparison between the glove perforation rate among perioperative nurses with single and double gloves during surgery. Am J Surg. 2012; 204:210-15.

16. Harnoß JC, Partecke LI, Heidecke C D, Hübner NO, et al. Concentration of bacteria passing through puncture holes in surgical gloves. Am J Infect Control. 2010; 38:154-8. 
17. Misteli H, Weber WP, Reck S, Rosenthal R, et al. Surgical glove perforation and the risk of surgical site infection. Arch Surg. 2009; 144:553-8.

18. Bekele A, Makonnen N, Tesfaye L, Taye M. Incidence and patterns of surgical glove perforations: Experience from Addis Ababa, Ethiopia. BMC Surg. 2017; 17:26 DOI: https://doi.org/10.1186/s12893-017-0228-8.
19. Kuroyanagi $N$, Nagao T, Sakuma $H$, Miyachi $H$, et al. Risk of surgical glove perforation in oral and maxillofacial surgery. Int J Oral Maxillofac Surg. 2012; 41:1014-1019.

20. Arowolo OA, Agbakwuru EA, Obonna GC, Onyia CU, et al. Safety of the surgeon: 'Double-gloving' during surgical procedures. South Afr J HIV Med. 2014; 15:144-7.

\begin{tabular}{|c|l|l|}
\hline \multicolumn{3}{|c|}{ AUTHORSHIP AND CONTRIBUTION DECLARATION } \\
\hline Sr. \# & \multicolumn{1}{|c|}{ Author-s Full Name } & \multicolumn{1}{|c|}{ Contribution to the paper } \\
\hline 1 & Priya & Study design, Data collection. \\
\hline 2 & Munir Ahmed Banglani & Concept, Discussion. \\
3 & Suneel Kumar Punjabi & Editing, References. \\
4 & Shazia Parveen & Intro, Literature searching. \\
\hline
\end{tabular}

